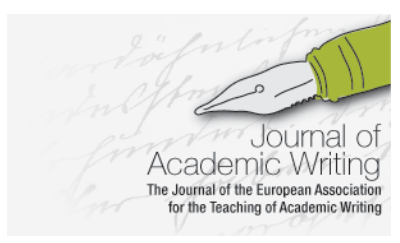

Journal of Academic Writing Vol. 10 No 1 WINTER 2020, pages 59-74 https://doi.org/10.18552/joaw.v10i1.602

\title{
Get a Room! How Writing Groups Aid the Development of Junior Academics' Writing Practice and Writer Identity
}

\author{
Jenny Mattsson \\ University of Gothenburg, Sweden \\ Emma Karin Brandin \\ University of Gothenburg, Sweden \\ Ann-Kristin Hult \\ University of Gothenburg, Sweden
}

\begin{abstract}
The present study revisits writing retreat participants who have spontaneously formed writing groups before or after attending a retreat hosted by the Unit for Academic Language at the University of Gothenburg, Sweden. All in all, 11 doctoral students and one postdoc were interviewed using a semi-structured interview model. The answers were thematically analysed based on Murray's (2014) concept of coherence in writing groups as well as parts of Aitchison and Lee's (2006) key characteristics of writing groups. The two main research questions posed concern (i) whether the informants have changed their writing practice and/or the way they think and feel about writing since joining a writing group, and (ii) whether possible changes have aided the development of their identity as academic writers. Results show that the informants have indeed changed central aspects of their writing practice and that this in turn has positively influenced how they now think and feel about writing. This has to some extent contributed to the informants' development of their writer identity; however, the present study also sheds light on the fact that more needs to be done at departmental levels across the university to make academic writing visible.
\end{abstract}

\section{Introduction}

Research writing is often considered "either deliberately or not, to be 'autonomous' (Street, 1984) or separate from the work of knowledge production and hence the practices of research, and understood in terms of individualized skills or deficits" (Aitchison \& Lee, 2006, p. 267). In spite of the growing body of work on academic literacies (e.g. Lea \& Street, 1998; Lillis \& Scott, 2007; Turner, 2012), which sees academic writing above all as a social practice connected to "social and institutional relationships ... and the writer's identity" (Creme \& McKenna, 2010, p. 153), research writing is still often addressed at universities in terms of individual writing abilities peripheral to a larger academic context. Especially junior academics (here including doctoral students) may struggle with "the emotions that writing stirs up and with the challenging process of developing a sense of self as an academic writer" (Cameron et al., 2009, p. 269). In addition, the physical conditions and workspaces of junior academics are not always conducive to focused writing. If we were to try and "legitimize writing" (Murray, 2015, p. 11) by viewing writing more as a shared academic experience and social act, and less as a product of individual struggles or flaws, it would be clear that academics need time, space and the right conditions to write (Borgström et al., 2015, p. 11). 
Academic writing retreats and writing groups are ways for academics to acquire this necessary time and space, as well as the conditions to focus exclusively on research writing (Moore, 2003; Murray, 2008, 2014; Murray \& Newton, 2009; Petrova \& Coughlin, 2012) and to reflect on writing in various ways in an atmosphere of trust, safety and empowerment (Grant \& Knowles, 2000). At the Unit for Academic Language (ASK), a university-wide unit providing writing and language development for students and staff at the University of Gothenburg (GU), Sweden, one-day structured writing retreats for doctoral students and researchers were implemented at the end of 2017, using a model developed at Queen Mary University of London, with structured writing, goal-setting activities, and some time for reflection and discussion. ${ }^{1}$ In the writing retreat model used at ASK, the day is structured into units, certain rules (e.g. no use of wi-fi or phones and no reading or talking while writing) are followed and goals are set before each writing session for optimal focus and elimination of typical work life distractions. All participants as well as the facilitator(s) sit facing each other in the same room according to "the typing pool" model, the purpose of which is to give a feeling of togetherness (Murray \& Newton, 2009, pp. 541-2). Writing retreats are thus a place where writers write together; there is a socializing of writing (Murray, 2015) through which "academics [move] from a position of peripherality into a community of writers" (Murray \& Newton, 2009, p. 542).

The present study focuses on those retreat participants who have spontaneously formed writing groups in connection to attending one of these writing retreats. As Murray (2014) notes, it is not an uncommon phenomenon for academics to do so in pursuit of (re-)connecting with the sense of community, connectedness, and concentration that they have experienced at the retreat. Invoking Virginia Woolf, one might say that each writing group thus creates and claims a physical as well as a conceptual room of their own.

There is an increasing amount of research on the benefits of academic writing groups (Aitchison \& Guerin 2014; Lee \& Boud 2003; Murray 2015; Reeves 2002; Sword 2017); however, "our understanding of when, how and why writing groups operate in academic scholarship is still fragmented and under-theorized" (Aitchison \& Guerin, 2014, p. 6). By revisiting some of the writing retreat participants who have formed writing groups at GU, Sweden, the present study hopes to add a relevant piece to the current picture of writing group research. With this article, we intend to show how being part of a writing group can benefit junior academics in Sweden in developing their writing, their thinking and feeling about writing and their identity as writers. We believe this can be a step towards legitimizing writing in this particular academic context and by extension other academic contexts.

In order to understand the when, how, why, and where writing groups operate in the particular context of GU, Sweden, we want to answer the following two research questions:

- Since being part of a writing group, have the junior academics in any way changed their writing practice and/or the way they think and feel about writing?

- If they have changed their practice and/or thinking and feeling, has this change in any way aided the development of their identity as academic writers?

In our view, every person who writes has a writing practice, good or bad, conscious or unconscious, efficient or inefficient. In our definition of writing practice, we include everything that has to do with how a person writes, for instance, the practical, spatial, social and structural dimensions to writing (without focusing on the quality of the product). Developing one's writing practice, however, has to do with becoming aware of and deliberately refining one's way of writing in various respects, i.e. "to consider [one's] writing practices in terms of specific behaviours, and critically review them" (Murray et al., 2008, p. 5). The aims of this development may be manifold, for instance to make the writing process easier, more efficient, productive or pleasurable.

Our definition of writer identity is quite broad. Having a writer identity as a junior academic means being in the process of developing "a sense of self as an academic writer" (Cameron et

${ }^{1}$ For more in-depth discussion of the theory and practice behind this model, see Moore 2003; Murray, 2008; Murray and Newton, 2009. 
al., 2009, p. 269), recognizing writing as a central part of one's work, and having attained a certain level of competence and confidence as a writer by attempting to practise one's own authoritative voice and to leave behind feelings of self-doubt (Antoniou \& Moriarty, 2008; Cameron et al., 2009; Creme \& McKenna, 2010; Ivanič, 1998).

To answer the research questions posed above, we conducted semi-structured interviews and the answers have been thematically analysed based on Murray's (2014) concept of coherence in writing groups, as well as parts of Aitchison and Lee's (2006) key characteristics of writing groups. Murray's (2014) concept of behavioural coherence is concerned with the writing group members' behaviour; the rules set by the group, the physical setting in which they meet, the people in the group, etc. all create a sense of consistency, continuity and discipline, much like a writing retreat does. Cognitive coherence is about how the writing group affects not only the group members' writing but also the way they think and feel about writing. Lastly, social coherence is created by the members "[accepting] the behavioural and cognitive framework" of the group (Murray, 2014, p. 103), sharing the writing group experience and conditions and thus establishing a sense of community. Relatedly, Aitchison and Lee (2006) find that socialising writing is fundamental to doctoral students' progress, and propose a set of key characteristics of research writing groups: Identification which concerns the sense of sharing, for instance, work contexts, research interests, and frustrations; Peer review ${ }^{2}$, i.e. students giving each other feedback on their texts; and Community, referring to an experience of connectedness among the group members. Finally, Normal business is about the need for incorporating research writing pedagogies into "the way we do things here" at departmental level, including "organizational workload and time management issues up to institutional policy and planning and down to the daily routinizing [of writing] into everyday work" (Aitchison \& Lee, 2006, p. 273).

\section{Methodology}

To be able to answer our research questions and to go into depth with these questions with each informant, a qualitative interview method has been used as a means to collect data. We e-mailed all writing retreat participants (approximately 150 individuals) who had been to ASK's writing retreats in 2018 or in the early Spring of 2019, in hopes of finding participants who had formed writing groups with colleagues before or after attending a retreat. We defined writing groups as any group (of a minimum of two members) of doctoral students and/or other academics meeting on a regular basis to write together in the same room (with or without giving peer feedback on texts). That is to say, all shapes and forms of writing groups were of interest to us.

We communicated that we wanted to ask some questions concerning their work in the groups as well as their thoughts on this way of working with writing. To avoid bias of any kind, further instructions ahead of the interviews were kept deliberately vague.

Altogether, we performed 10 interviews with 12 informants from nine separate writing groups (two participants were in two separate groups). ${ }^{3}$ Out of these 12 informants, 11 were doctoral students and one a postdoc. See Table 1 below for an overview of the informants.

\footnotetext{
${ }^{2}$ In the present study, we do not discuss Aitchison and Lee's characteristic of peer review as only one of the writing groups we have interviewed has any element of peer response in their group meetings.

${ }^{3}$ Some interviews were held in Swedish and relevant quotes have then been translated into English; some interviews were held in English.
} 
Table 1

The Informants, their Position and Discipline/Faculty

\begin{tabular}{|l|l|l|}
\hline Informant & Position & Discipline/Faculty \\
\hline 1 & Doctoral student & Medicine \\
\hline 2 & Doctoral student & Education \\
\hline 3 & Doctoral student & Business, Economics, and Law \\
\hline 4 & Doctoral student & Social Sciences \\
\hline $6 \mathrm{a}+\mathrm{b}$ & Doctoral students & Education \\
\hline 8 & Doctoral student & Natural Sciences \\
\hline $9 \mathrm{a}+\mathrm{b}$ & Doctoral students & Social Sciences \\
\hline 10 & Doctoral student & Education \\
\hline 11 & Postdoc & Medicine \\
\hline 12 & Doctoral student & Education \\
\hline
\end{tabular}

Note. Interviews with informants 5 and 7 were planned but ultimately cancelled.

All interviews were held on university premises, with two hours allotted for each interview. Prior to the interviews, the informant(s) were asked to read and sign a consent form detailing the aim of the study, guaranteeing anonymity and regulating data collection and data use. Our aim with the interview set up was to have a relaxed, informal conversation with the informants and to be flexible enough to sometimes let them lead the conversation and select what issues to address (Denscombe, 2017, p. 221). To this end, a semi-structured interview model was used. Two interviewers were present in most interview sessions, in order to share note-taking duties and to uphold a conversational atmosphere.

The interview questions (see Appendix for full Interview Guide) were structured into five main parts: (i) the informant's background and experiences of attending an ASK writing retreat; (ii) the motivation behind as well as the practicalities surrounding the writing group; (iii) the social and collaborative aspects of the writing group; (iv) a focus on writer identity; and (v) the departmental context of the writing group. These questions were based on Murray's (2014) concept of behavioural, cognitive, and social coherence as well as parts of Aitchison and Lee's (2006) key characteristics of writing groups, namely identification, community, and normal business.

The recorded interview material amounts to approximately 17 hours in total. Rather than transcribing the full interviews verbatim, we developed a thematic matrix and transcribed, as well as performed a thematic analysis of, those parts of the interviews focusing on the following six themes: Motivation behind forming/participating in a writing group; Changed writing practice; Changed thinking and feeling in connection to writing; The social dimension of the writing groups; Writer identity; and The view of writing at departmental level. In the next section, we report on the informants' answers in connection to these themes.

\section{Results}

Each of the writing groups represented consists of 2-5 participants, most of whom are doctoral students. The starting date for the groups differs from a couple of years ago to quite recently, with most groups being formed in connection to or shortly after an ASK retreat in 2018 or 2019.

The following account of the results of the semi-structured interviews is based on the six themes mentioned above and presented in that same order.

\section{Motivation behind the writing group}

Some benefits of writing retreats that may be transferred into writing groups, apart from an increase of research activity and publishing output (Murray \& Newton, 2009), are academics' reconnection with writing and with themselves as writers (Moore, 2003). These benefits result 
from academics reflecting on their own writing processes as well as meeting and talking about writing with colleagues from across their university.

The writing retreat pedagogy is mentioned by most informants ${ }^{4}$ as the main motivation for initiating a writing group, and two particular aspects are frequently brought up: first, the structure of the day (the strict time keeping, the rules of no phones, no wi-fi, no reading, etc.); and second, the individual goal-setting before each writing session. Informant (I) 2 and I12, below, were able to find a focus at the writing retreat they had never experienced before:

I could concentrate at the writing retreat in a way I haven't been able to do before or after - I learnt that I can focus. (I2)

Breaking [the work] up into reachable goals was new for me [at the retreat] and is something I use now. (I12)

The informants, below exemplified by 13 and 18 , also experienced a sense of positive peer pressure and focus at the retreat, mainly through sitting together with other writers when writing, which in turn made them think about the writing process somewhat differently:

I learned that I like writing in a group. That's why we started our writing group. (I3)

There were no excuses; everyone else was sitting there writing. (18)

Despite some negative experiences of certain aspects of the retreat, for instance the structure being too rigid and resistance to sitting in the "typing pool" (Murray \& Newton, 2009, p. 541), most of the informants report that they left the writing retreat with new ways of thinking about writing and that they adhered to most parts of the retreat concept when forming their own writing groups. For instance, they state that they plan fixed time-slots for the writing group meetings into their calendars. They also refer to the importance of physically leaving their regular offices to minimize distractions from their ordinary work environment. The writing group meetings are generally divided into units and follow the writing retreat rules of not speaking while writing and not using phones or the Internet.

\section{Changed writing practice}

Being part of a writing group seems to have changed the informants' writing behaviour (see behavioural coherence, Murray, 2014) in many ways. The informants state that they have made changes to the way they structure their writing activities, for instance, by scheduling a time and place for writing into their weekly work. As I12 says below, by literally making room for writing in her calendar, it actually gets done:

Scheduling writing time helps, planning it in the calendar. I do it instead of thinking that I should. (I12)

Structuring the actual writing day into parts is also mentioned as an important change to the informants' writing practice. I1 talks about how much easier she now finds it to get started on her writing.

When you get the time, the other barriers fall down in a way and then you sit there for 45 min and write. If you hadn't been that focused it's so easy to do something else because the threshold to start writing is so great, but if I've said that I'm going to do it for 45 min, I just do it. (I1)

\footnotetext{
${ }^{4} \mathrm{~A}$ few informants had started their writing groups prior to coming to a writing retreat and in these cases the motivation was reading about writing group models or hearing about the models from peers or supervisors.
} 
Another important change to the informants' writing practice is booking a room other than their ordinary office for their group; alternatively, as I4's group has done, staying in one's office space but signalling that this space is now a room for writing only:

We stick a 'do not disturb' note on our door when we write. (14)

Making physical room for writing in this way serves the double purpose of outwardly communicating the importance of undisturbed writing and inwardly acknowledging a sense of community and legitimacy in the writing practice.

The informants state that by planning their writing and making it a regular part of their working week, they now prioritize writing more. Their writing has gained visibility in their work lives and can be prioritized before other work tasks. This newfound privileging of writing (Murray, 2015) is mentioned by $16 \mathrm{a}$ and 18 , below.

I prioritize differently now; writing is not something I do on the side, but it's a central part of what I do. (I6a)

I know now that I have to make time for writing to get it done. (I8)

Because the writing groups form a space where writing is prioritized, they have brought regularity and predictability to the informants' writing process. After joining the group, the informants state that they have now become better at facing obstacles instead of running away; they do not need to wait for inspiration and they do not rely on external stimuli to be able to write. This is how 110 describes the function of her writing group:

Maybe that's the reason why the [writing] group works...? It's like a wood workshop, it's where we come to fix stuff, which is really what writing often is ... I think it's because people come back to this place because they need help; they know that now it's fixing time. (I10)

The regularity and practicality of the writing group work seem to have created a consistency in the informants' writing process that makes the writing itself much easier, and this may in turn be a reason why the writing group method is perceived to work well.

The consistency in the writing activity has also made the actual writing process more visible for some of the informants, and as a consequence they now view writing more as an ongoing process and not merely an end product:

I know now that I have to make time for writing to get it done, decide that I'll sit for an hour and write. The aspect of time is important for me. I see writing more as a process now, step by step. (18)

I'm thinking a bit more about the writing process now than the product by setting more goals. (I2)

In the following, we will see how the informants' changed writing behaviour has influenced their thoughts and feelings connected to writing.

\section{Changed thinking and feeling about writing}

In structuring and prioritizing writing more and experiencing a clearer consistency in writing, the informants convey that they have also changed the way they think and feel about writing (see cognitive coherence, Murray 2014). The informants state that the writing groups have made them experience a greater concentration and focus when writing. This, in turn, has led to less of a guilty conscience and a way to overcome writers' block: 
Through structuring and organising my time, I see that now I've actually done this and now it's good enough; I get less guilty conscience. (I1)

I can overcome writer's block and other obstacles now because I can't escape from writing. (12)

In a wider sense, by being increasingly able to concentrate and fight against procrastination, many informants experience a greater confidence in themselves. 14 talks about being able to detach herself from her writing:

I have a greater distance to my writing now; it's not my soul, I'm better at receiving criticism ... I see a difference now between who I am and what I do. (I4)

The increased confidence that nearly all our informants express in turn adds to an increased sense of well-being; simply put, being part of a writing group and structuring writing into their weekly schedules make the informants enjoy writing more as "[i]t stops you spending unproductive time worrying about not writing" (Murray, 2014, p. 103). As 13 puts it, the consistency of writing now makes her feel better about writing. 112 adds that her mindset and confidence about writing have changed and that she appreciates the writing process more:

[Because I do this every week] writing is much more pleasure and not so much pain. (I3)

I learnt to like writing more, I don't feel that it's such a burden. Before I was almost afraid, now I feel that I can just write as much as I can and then I can always go back and change it and improve it. So I think my mindset about writing has changed a bit in terms of endurance. (I12)

I11 has changed her view of writing completely since being in a writing group; it used to be something she found challenging but now, with a newfound structure around writing, she looks forward to it:

My Thursdays [writing together with a colleague] have helped me start thinking about writing as being fun. I have started to enjoy writing. Before it was just a burden. I think the writing process is difficult but because I do this every week it becomes more fun. (I11)

Clearly, finding joy in the writing process is a significant aspect of a well-working writing group. Sword (2017) has similarly found that "[w]hat nearly all successful writing groups have in common is a shared sense of generosity, pleasure, and even fun" (p. 139).

\section{The social dimension}

Each academic writing group "form[s] a social context or community within which members can learn together from each other" (Aitchison \& Lee, 2006, p. 274). Together, the group members create a safe space where they can be anonymous if they want to but share thoughts and goals if they so choose: "a combination of accountability and anonymity" (Murray, 2014, p. 105). This social dimension (cf. social coherence, Murray, 2014) thus concerns the setting in which the writing takes place and the people creating this setting.

The social aspect that seems to have contributed most to the cognitive and behavioural changes is the sense of accountability, or "peer group pressure in the nicest sense" (Murray, 2014, p. 105). All of the informants report that they experience a greater focus simply from physically sitting together with other people and that this in turn adds to a sense of legitimacy and of being accountable to each other, similar to their experience at the writing retreat: 
I think it helps me to be in a group; I can write for a longer time and focus better. (I3)

We do it because we're doing it together. (I6b)

I felt a sense of collective concentration in the group. (18)

By sharing not only a physical space but also thoughts and feelings connected to writing, the writing group enriches the group members' writing experience; they share an identity of similar work contexts, life experiences, etc. (Aitchison \& Lee, 2006, p. 272) and they are made accountable to each other by their involvement in the group. Equally, the group identity and accountability give its members a sense of sustainability:

It's a kind of social pressure, you can't escape, and you feel connected with others. We all struggle with our texts and we sort of do it together even if we're doing different things. (I12)

I think it's the comradery, it's really nice to be able to complain when it doesn't go well. It's nice to share joy and to know that people listen to you ... That's why the writing groups are so good, you could see everybody else being frustrated, it's nice to have a safety net. (I10)

In contrast to these positive social writing group experiences, there are examples of difficulties with forming and sustaining a writing group. For instance, 112 , who experiences a great focus when writing in a group also highlights the problems that arise when members do not adhere to the rules set by the group:

It depends a lot on the people in the group; there are bad experiences of people coming late, being chatty, etc. (I12)

I10 who is quoted above, saying that the people in the group were very important, goes on to say that when the group grew from just a few to about 10 members, it did not work as well anymore. This informant felt she had to take on the role of group leader more than before and that this decreased her own motivation. A similar account is given by 12 :

When we were many for a short time it wasn't the same emotionally. It worked but I had to explain things more and it felt more like work. The good thing with the small group is that we're having fun while we work. (I10)

Leading our own writing group went well but I felt a bit dictatorial ... It was difficult to keep the discipline, an uncomfortable role, but time-keeping is an important part of it. I didn't experience the same [positive] social pressure ... because I was the leader of the group. (12)

Evidently, administrating and sustaining a writing group is not necessarily effortless. This, according to our informants, is mostly because of an uncertainty in the group concerning who will do what. As we can see above, acting as a group leader can be an unexpectedly demanding and undesirable task. Other challenges to sustaining the group is, for example, when members leave the group as II states, or, as I10 emphasizes, when the social dimension is experienced as something negative:

When one person leaves the group, the whole group falls apart. You may think that you don't need the others to focus because you're on your own, but then you're not focused at all. (I1)

Maybe sometimes the social element is too hard for some if they're overwhelmed by [other] deadlines. (I10)

The social dimension of writing groups is fundamental; if the social aspects of the groups do not work, and if there is no support available, it may become impossible to sustain the group. 
Similarly, Aitchison and Guerin (2014) establish that "writing groups are not for everyone, and without support and know-how many experience frustrations in their attempts to establish and maintain groups" (p. 7).

\section{Writer identity}

As we have seen, all of our informants report changes in their writing practice and the way they think and feel about writing since joining a writing group. What the present study also wants to investigate is whether this change in any way has helped the informants individually develop "a sense of self as an academic writer" (Cameron et al., 2009, p. 269). When asked whether they see themselves as writers, only two of our 12 informants answer in the affirmative:

Yes, I actually do, mostly because my son wants to know what I do. "Mummy's writing a book, writing is mummy's job". But a writer ... yes writer, a person who writes and erases and rewrites. (16a)

I feel like a writer, I think my work is similar to the work of an author ... I think that has to do with the fact that I'm writing so much more now in the writing group, it has helped me. (I1)

A majority of the informants do not see themselves as writers primarily but more as researchers who write. Their answers do tell us, however, that since joining a writing group their view of their own writing has changed and their confidence in themselves as writers has increased. Cameron et al. (2009) found that "developing an identity and voice as an academic writer results from the process of coming to terms with writing emotions and developing procedural and technical writing know-how" (p. 279). In our study, we note that actively engaging in such a process, in this case through working in writing groups, adds to a sense of self as a writer, whether or not you label yourself a "writer":

I think the writing group has changed my view of myself as a writer in that I like it more and I feel it's important to spend time on it. (I12)

Even though I have written a lot I didn't used to feel like a writer. I wanted to become a researcher. Now I realize that [research] is about writing and it doesn't scare me anymore. (I3)

Notably, many of the informants state that they used to enjoy the act of writing as undergraduates or in other lines of work; their "earlier, more confident writerly [selves]" (Creme \& McKenna, 2010, p. 162) enjoyed writing but now as junior academics they no longer do:

I used to feel like I was a writer when I was a master student. I was very proud of my writing. As a doctoral student I haven't experienced that enough. (I9a)

A PhD is weird ... you lose some part of your competency, a weird loss of identity, and that's why people get stressed. I don't feel as confident anymore. (I10)

Defining oneself as a writer is a complex and partly personal matter, and "issues surrounding writing and identity, particularly the notion of 'myself as a writer', are rather new [for junior academics]" (Creme \& McKenna, 2010, p. 159). Also, development of writer identity cannot occur in a vacuum; junior academics need to feel that they are allowed to identify as writers by their academic environment: "each instance of writing is located within a particular context that encompasses ... social and institutional relationships, with a stress on relations of power, and the writer's identity" (Creme \& McKenna, 2010, p. 153). Below we will connect the concept of the informants' writer identity with their departmental association.

\section{The departmental level}

While most of our informants answer no to the question of whether they see themselves as writers, they still discuss this issue at some length and problematize it, often connecting their own lack of writer identity to academia in general: 
I don't really feel like a writer in the work that l'm doing now, I wish we were allowed to feel more like writing professionals ... and to develop as writers. (I9b)

The confidence the informants have found in the writing groups is something they have not previously been able to attain at their respective departments because writing is rarely made visible there. Most of the informants state that writing and especially the writing process are not talked about at their departments, i.e. there is an "invisibility of the act of writing" (Murray, 2015, p. 7). As Starke-Meyerring (2014) has found, writing is often "silenced in institutional environments" (p. 70). However, this is "not necessarily the invention of those who currently work in them [but] inherited institutional environments" that have evolved over time and that, regrettably, are often not reflected upon (Starke-Meyerring, 2014, p. 65).

The informants discuss the tendency at departmental level to focus on the publication of writing over the writing process, and the fact that writing is only acknowledged when published. This is, for example, illustrated by I6b:

Writing is seen as a private matter, something you do on weekends and evenings and don't talk so much about - but our department celebrates when a researcher has published an article. There's status in publishing but not in writing. (I6b)

Some further insights into how writing is viewed at the informants' respective departments are illustrated below. The informants mention the fact that writing and the writing process is not talked about:

We don't talk about writing at the departmental level and I think that's a problem. My supervisor doesn't see it as a process, he sees it as 1 . do research, 2. write up the research. (18)

I think there's too much focus on what you write and not enough on how you write it. (I12)

The informants' accounts suggest that their departments view writing as a mere tool for "writing up" research, a metaphor which "obscures the fact that doctoral writing is thinking. We write to work out what we think" (Kamler \& Thomson, 2006, p. 4). Our informants all wish for the thinking and writing process to be acknowledged at the departmental level as essential to doing research. II and I2 below would like to see further legitimization of writing at their departments:

I wish writing was prioritized more at my department, that the benefits of focused writing in general were acknowledged and prioritized at all levels of academia, from the head of department and down. (I1)

We don't talk so much about writing at my department ... it's a bit of a mystery how writing gets done ... I'd be happier if writing was seen more as a common process and a common concern at the department. For example, once a week a room could be booked and anyone could go there to write. (12)

Our informants clearly indicate the need for writing to be made visible and incorporated at the departmental level. It seems that writing groups in many ways "act as enabling microenvironments [and that] in this way, writing groups function ... as privileged spaces" (Lee \& Boud, 2003, p. 196), a room where you go to write as well as to be part of a writing community. The informants have experienced the benefits of a writing community, and are keen to continue to develop their own writing, while also expanding this community through conversation with colleagues at all university levels. 


\section{Conclusion}

With structured academic writing retreats as a backdrop, the present study gives insight into junior academics' experiences of forming, participating in, and sustaining academic writing groups. The two main questions posed were, (i) whether the informants, since joining a writing group, have changed their writing practice and/or the way they think and feel about writing and, if so, (ii) whether these changes have aided the development of the informants' identity as academic writers.

The first question is answered in the affirmative; the informants declare to have changed both the way they practice writing and the way they think and feel about writing. Being part of a writing group has made writing a more structured and prioritized part of their everyday work life, which in turn has made them think about writing more in terms of process than product. Their writing confidence is greater, and they enjoy the process of writing more, both of which are direct results of the social dimension of the writing group, i.e. the people with whom, and the setting in which, the writing takes place. This "shared practice gives [the writing group] a kind of legitimacy" (Murray, 2014, p. 103); however, as with all interpersonal experiences, it is also fragile and sustaining a writing group sometimes proves difficult.

The second question posed in this study concerns whether their engagement in a writing group has aided the development of the informants' identity as academic writers. Naturally, this question cannot be answered with simply yes or no. Some of the informants have developed a sense of being writers because writing is now a more central, consistent, legitimized, and enjoyable part of what they do. For them to fully take on a writer identity and feel that writing is truly a legitimate part of their work and identity, however, writing still needs to be made an explicit part of the university's "normal business" and "the way we do things here" at departmental level (Aitchison \& Lee, 2006; Lee \& Boud 2003). In conclusion, we believe that writing needs to be made more visible at many departments (Mitchell, 2010) and that there is a need for a more honest conversation, as well as a certain questioning of norms, about writing at all levels of academia. We also encourage academic writing support at universities everywhere to continue raising awareness and providing safe spaces for conversations about writing, not least by offering junior academics a physical as well as a conceptual room to write in.

The present study is only a glance at how writing groups operate for a small number of individuals over a limited period of time. In addition, our participants are self-selected and therefore another set of participants might have provided less positive and/or other experiences of working in writing groups. Future research needs to investigate the more long-term benefits or detriments of academic writing groups, but thus far we can safely endorse Reeves's (2002) advice for academic writers in pursuit of finding a writer identity: "Make a place for your writing, a sacred place where you go with joy as your companion, not dread or guilt or "shoulds" riding your shoulders like weights of sand" (p. 3). 


\section{References}

Aitchison, C., \& Lee, A. (2006). Research writing: Problems and pedagogies. Teaching in Higher Education, 11(3), 265-278. http://doi.org/10.1080/13562510600680574

Aitchison, C., \& Guerin, C. (Eds.). (2014). Writing groups for doctoral education and beyond. Routledge.

Antoniou, M., \& Moriarty, J. (2008). What can academic writers learn from creative writers? Developing guidance and support for lecturers in higher education. Teaching in Higher Education, 13(2), 157-167. https://doi.org/10.1080/13562510801923229

Borgström, B., Helin, J., Norbäck, M., \& Raviola, E. (Eds.). (2015). Skrivande om skrivande. Studentlitteratur.

Cameron, J., Nairn, K., \& Higgins, J. (2009). Demystifying academic writing: Reflections on emotions, know-how and academic identity. Journal of Geography in Higher Education, 33(2), 269-284. http://doi.org/10.1080/03098260902734943

Creme, P., \& McKenna, C. (2010). Developing writer identity through a multidisciplinary programme. Arts \& Humanities in Higher Education, 9(2), 149-167. http://doi.org/10.1177/1474022210361456

Denscombe, M. (2017). The good research guide: For small-scale social research projects (6th ed.). Open University Press.

Grant, B., \& Knowles, S. (2000). Flights of imagination: Academic women be(com)ing writers. International Journal of Academic Development, 5(1), 6-19. http://doi.org/10.1080/136014400410060

Ivanič, R. (1998). Writing and identity: The discoursal construction of identity in academic writing. John Benjamins.

Kamler, B., \& Thomson, P. (2006). Helping doctoral students write: Pedagogies for supervision. Routledge.

Lea, M., \& Street B. (1998). Student writing in higher education: An academic literacy approach. Studies in Higher Education, 23(2), 157-172. https://www.kent.ac.uk/teaching/documents/qualifications/studwritinginhe.pdf

Lee, A., \& Boud, D. (2003). Writing groups, change and academic identity: Research development as local practice. Studies in Higher Education, 28(2), 187-200. https://doi.org/10.1080/0307507032000058109

Lillis, T., \& Scott, M. (2007). Defining academic literacies research: Issues of epistemology, ideology, and strategy. Journal of Applied Linguistics, 4(1), 5-32. https://doi.org/10.1558/iapl.v4i1.5

Mitchell, S. (2010). Now you don't see it; now you do. Writing made visible in the university. Arts \& Humanities in Higher Education, 9(2), 133-148. https://doi.org/10.1177/1474022210361452

Moore, S. (2003). Writers' retreats for academics: Exploring and increasing the motivation to write. Journal of Further and Higher Education, 27(30), 333-342. https://doi.org/10.1080/0309877032000098734

Murray, R. (2008). Writer's retreat: Reshaping academic practices. Educational Developments, 9(2),14-16. http://www.seda.ac.uk/resources/files/publications 11 eddev9 2.pdf 
Murray, R. (2014). Doctoral students create new spaces to write. In C. Aitchison \& C. Guerin, (Eds.), Writing Groups for Doctoral Education and Beyond (pp. 94-109). Routledge.

Murray, R. (2015). Writing in social spaces: A social processes approach to academic writing. Routledge.

Murray, R., Thow M., Moore S., \& Murphy M. (2008). The writing consultation: Developing academic writing practices. Journal of Further and Higher Education, 2(32), 119-128. https://doi.org/10.1080/03098770701851854

Murray, R., \& Newton, M. (2009). Writing retreat as structured intervention: Margin or mainstream? Higher Education Research and Development, 28(5), 541-553. https://doi.org/10.1080/07294360903154126

Petrova, P., \& Coughlin, A. (2012). Using structured writing retreats to support novice researchers. International Journal for Researcher Development, 3(1), 79-88. https://doi.org/10.1108/17597511211278661

Reeves, J. (2002). Writing alone, writing together: A guide for writers and writing groups. New World Library.

Starke-Meyerring, D. (2014). Writing groups as critical spaces for engaging normalized institutional cultures of writing in doctoral education. In C. Aitchison \& C. Guerin, (Eds.), Writing Groups for Doctoral Education and Beyond (pp. 65-81). Routledge.

Street, B.V. (1984). Literacy in theory and practice. Cambridge University Press.

Sword, H. (2017). Air \& light \& time \& space: How successful academics write. Harvard University Press.

Turner, J. (2012). Academic literacies: Providing a space for the socio-political dynamics of EAP. Journal of English for Academic Purposes, 11(1), 17-25. https://doi.org/10.1016/i.jeap.2011.11.007 


\section{Appendix: Interview Guide}

[1. Background: who is the respondent and what was his/her experience of the ASK writing retreat]

- Name? Department?

- What ASK retreat did you attend (what semester)?

o How did you find out about the retreat?

o Why did you sign up for it?

o What were your expectations?

o What did you think about the retreat? What was your overall experience of the day?

o Were your expectations met or did anything surprise/disappoint you about the retreat?

- Do you think about writing differently now compared to before the retreat? Are you approaching writing differently now than before the retreat? (cf. the writing process/practice; setting goals; writing takes time; not reading while writing; minimizing distraction; etc.)

\section{[2. The writing group - motivation and practicalities]}

- Do you have any previous experience of writing retreats/writing groups?

- How did the writing group that you are now participating in form itself?

o Who took the initiative (you, colleague, head of department, etc.)?

- Did you start the writing group before or after attending an ASK retreat? If before, have you changed anything in the writing group since attending the ASK retreat (e.g. the structure, number of participants, etc.). Why? If after, did you have this idea before or was the retreat the first time you started thinking about forming or joining a writing group?

- Tell us a bit more about the writing group:

Who's in the group?

How often do you meet?

For how long? Where?

What rules do you have (if any)?

Do you do any goal-setting?

Do you include any form of peer response?

What do you think works and what doesn't work? 


\section{[3. The writing group - socializing writing; a collaborative community of writers]}

- How do you think writing together as a group works? What are the pros and cons?

- Writing aside, do you also talk about writing in the writing group?

- If you do, is that a structured/planned part of the session or a spontaneous thing?

o Do you have coffee breaks/lunch breaks together during your meetings? If so, what do you tend to talk about then? Do you (as a group) try to steer the conversation towards writing?

o Do you think talking about writing with other writers helps? In what way?/ Why not?

- Has being part of a writing group in any way changed/developed your writing practice (further), e.g. in terms of how you start writing; how you deal with writer's block; "ugly writing"; process vs. product - do you view writing as your tool (through which you think, create content, move forward in the thinking process, etc.) or are you more focused on the finished text; the end product? [Practice]

\section{[4. View of self as a writer - Writer identity]}

- Has being part of a writing group in any way changed your view of yourself as a writer? In what way?/Why not? [Identity]

- You are a person who writes as part of your profession - do you think of yourself as a writer? (or more as a researcher documenting your work through writing)? Why?/Why not?

o How did you view yourself before attending the retreat and/or starting/joining a writing group? Any change?

[5. The writing group - Connected to the "normal business" and "the way we do things here" at the departmental level (Aitchison \& Lee 2006)]

Focus on the writing group

- Who knows about the writing group at your department? What do they think? Do you get any questions about the group?

- Are others welcome to participate in these writing groups, i.e. is it open to administrative staff, master's students, etc.?

- Do colleagues/head of department/others seem to be interested in the writing group and what it is that you are doing there?

- Has anyone else initiated a writing group at your department (before or after you did)?

Focus on writing as part of the working day

- Do you feel that writing is a part of a normal workday for you and your colleagues?

- Is writing viewed as important and as something that is prioritized by your department?

o Do you talk about (academic) writing in general at your department? 
o How is (academic) writing viewed?

o Can you give examples of when writing is prioritized and not? For example, are teachers/researchers encouraged to set aside time for writing during a period of less teaching, to apply for research grants, etc.?

o Has your department had any type of writing retreat initiated by the head of department or similar (before or after the ASK retreat)?

o Do you think that the department's view of writing has in any way changed since your writing group formed? For example, are colleagues talking more about writing and are they talking about writing in a different way than before?

- Would you like anything to change concerning the view of writing at your department? 